\title{
Underemployment and the Lack of Wage Pressure in the UK
}

\section{David N.F. Bell}

Division of Economics

Stirling Management School, University of Stirling, IZA and CPC

and

\section{David G. Blanchflower}

Bruce V. Rauner Professor of Economics, Department of Economics, Dartmouth College,

Division of Economics, Stirling Management School, University of Stirling, Bloomberg, IZA and NBER

JEL Classifications: J11; J21; J31; J61

We thank NIESR Director Jagjit Chadha and Amit Karafor helpful comments 
Bell D \& Blanchflower D, Underemployment and the Lack of Wage Pressure in the UK, National Institute Economic Review, 243 (1), pp. R53-R61. Copyright (C Authors 2018. Reprinted by permission of SAGE Publications.

\begin{abstract}
In this note, we focus on underemployment as a potential cause of lower wage growth, which itself may have deeper causes, but which has, we would argue, demonstrably changed since the 2008 recession. The gap between our measures of the number of additional hours required by those who want more hours and the number who want less has narrowed recently. Neither have returned to their pre-recession levels. In our view, underemployment remains a major factor in explaining the $2 \%$ wage norm that continues to exist in the UK.
\end{abstract}

Keywords: unemployment, underemployment, wage inflation, hours, anchoring, heuristics

JEL Codes: J31, J42, J22, E31 
A major puzzle across OECD countries is why nominal wage growth has been so weak given the rapid declines in the unemployment rate in the years since its peak. In the United States the peak unemployment rate was $10 \%$ in October 2009 while in the UK it was $8.5 \%$ in October 2011. At the time of writing, the unemployment rate in the US is $4.1 \%$ and in the UK, is $4.3 \%$. But there is little sign of any pick up in wage pressure, as occurred in previous recoveries. The drop in the unemployment rate from $6.5 \%$ to around $4 \%$ in the past would have generated a burst of wage inflation, but not this time around, in any country, including the US and the UK. A wage norm of around $2 \%$ wage growth appears to have become embedded around the world. Nominal wage settlements appear to have become "anchored" around this level. Real wage growth, post-recession has been especially weak in the UK but less so in the US.

As shown in Figure 1, from March 2001 to March 2008, at the beginning of the Great Recession, average nominal annual wage growth in the UK, as measured by the national statistic Average Weekly Earnings (AWE) was around 4.3\%. For the period from March 2008 to March 2017, the equivalent rate was 1.9\%, less than half of the pre-recession growth rate. In the earlier period, the average unemployment rate was 5.2\%. In the period from March 2008 to March 2017, the average unemployment rate was $4.9 \%$. The latest data point available to us, for October 2017, AWE total pay growth was 2.3\% with an unemployment rate for August to October 2017 of $4.3 \%$. In January 2007, wage growth was $6.9 \%$ and the unemployment rate was $5.5 \%$.

Recent data from the pay experts XpertHR shows that the pay norm of 2\% that they have observed for years in pay settlements continues. "Despite unemployment falling and inflation rising through the year, employers have refused to budge from the muted pay increases they have favoured for a large part of the past five years," they said. This inertia that employers wage offers reflect an anchoring-and-adjustment heuristic. Unable to generate fully informed expectations, they try to behave rationally, but fall back on norms if the costs of forming these expectations appear prohibitive (Roos and Luhan, 2008).

Figure 1 also plots UK real wage growth, which has been negative for the seven months from April-October 2017. Real weekly wages at constant 2015 prices were $£ 490$ per week in October 2017, down from $£ 522$ per week in February 2008, just before the Great Recession started. So, real earnings are about $7 \%$ below what they were nearly a decade ago.

In the US monthly average weekly earnings of private sector production and non-supervisory workers, who are about $80 \%$ of all private sector workers and around $70 \%$ of the total workforce, averaged $4.0 \%$ in 2006 and 2007 in the two years before the start of the Great Recession, when the unemployment rate averaged 4.6\%. Over the two-year period December 2015 to November 2017, monthly wage growth averaged $2.4 \%$ while the unemployment rate over the same period averaged $4.6 \%$.

This recent experience suggests that unemployment is a weak predictor of nominal wage pressure. It fares little better in predicting real wage growth. For the period from January 2006 (when the Office of National Statistics began to publish real average weekly earnings) to March 2008 , real weekly earnings were growing at an average annual rate of 1.6\%: from March 2008 to March 2017, real earnings growth fell to an average rate of $-0.2 \%$. The decline in real living standards implied by the post-recession wage data is unprecedented 
The unemployment rate no longer predicts either real or nominal wage pressure. It seems to seriously over-estimate it. Other measures of the external labour market, previously believed to capture the extent of labour market slack fare little better. Compared with the pre-recession period, economic inactivity rates were virtually unchanged in the UK post-2008, at 36.4 per cent. The short-term (less than 6 months) unemployment rate averaged 3.2\% between 2001 and 2008 and $3.5 \%$ since then, hardly a sufficient increase to induce a 50\% reduction in nominal wage growth.

There is a widespread belief that the forecasting performance of pre-recession models of wage growth has been so poor post-recession that some structural change has taken place which undermines the usefulness of these models. In a recent speech, Michael Saunders of the Monetary Policy Committee argued that these models fail to capture "greater labour market flexibility and insecurity, extra labour supply, increased underemployment, broader educational attainment, and changes to the tax and benefit system" (Saunders, 2017).

This is a wide set of possible causes. How they have interacted with the recession is critical to an understanding of the fall in wage growth from 2008 onward. For example, the increase in self-employment has been associated with greater labour market flexibility, but the increasing share of the self-employed in the UK workforce has been on a steady upward trend during the first two decades of this century. This trend was not affected by the recession. Therefore, unless there was a marked change in the nature, rather than the volume, of self-employment around the time of the recession, it is difficult to link the sudden drop in wage settlements to the evolution of self-employment.

The main reason that real wages haven't risen is presumably that labour productivity has also been flat. There are obviously a number of deep factors driving the labour productivity puzzle but we have to accept that real wages and labour productivity are closely linked. In addition, the labour share has been remarkably stable in this period, because increased numbers in employment have compensated for the decline in real wages. The nominal part of the wage story is presumably connected to the attainment of price stability. We simply do not expect price inflation to hit $10 \%$ any more, and this may partly explain why wage settlements seem to have been anchored around $2 \%$ for several years.

There may also be a trade-off between employment and real wages. Faced with uncertain returns to capital investment, firms may have preferred more workers post-recession that higher paid workers. Our results are consistent with the findings of Belfield et al (2017) who recently reported that there has been a dramatic rise in the proportion of low-wage men who are working part-time. Their analysis is based on the UK's Family Resources Survey (FRS). This is a repeated cross section containing between 20,000 and 25,000 households in each financial year. They find that the decline in mean hours at the lowest three deciles of the male hourly wage distribution was especially marked. This increase is entirely consistent with our findings from the underemployment data we examine.

In this note, we focus on underemployment as a potential cause of lower wage growth, which itself may have deeper causes, but which has, we would argue, demonstrably changed since the 2008 recession. Definitively identifying these deeper causes is beyond the scope of this paper, but measures of underemployment are reasonably easy to calculate from the Labour Force Survey and therefore can provide policymakers with timely indications of wage pressure. 
Another factor is likely to be the public sector pay freeze in operation in the UK since the coalition government took office in 2010 has helped to lower the pay norm. Recent evidence suggests that over the last 30 years, private sector wage increases have tended to lead public sector wage increases (Dolton, Hantszche and Kara) although there is some short-term feedback from the public to the private sector. Recent dynamics from the ASHE pay data indicate that pay increases in the public sector were higher than in the private sector in the period before the Great Recession and slower thereafter. According to ASHE, UK median growth rate of gross nominal weekly earnings was 5\% from 2002-2007 in the public sector versus $3.9 \%$ in the private sector. For the period $2010-2014$ they were $1.8 \%$ and $2.2 \%$ respectively, while for the years $2015-2017$ they rose to $2.0 \%$ and $2.8 \%$ respectively. This meant that the public sector was less attractive relative to the private sector than it had been in the past, as a place of alternative employment. This has occurred despite the fact that union density rates are markedly higher in the public sector (52\%), than in the private (13\%).1

Other factors which may matter include the influx of workers from Eastern Europe, which has helped to contain wage pressure (See Blanchflower and Shadforth, 2008). Even though the unemployment rate itself has fallen, there is evidence that there has been a pick-up recently in the fear of unemployment (Blanchflower, 1991). Figure 2 illustrates. It shows a monthly series of responses from consumers from a survey conducted by the European Commission in every member country. It plots for the UK and the Eurozone the answers to the question "what do you think is going to happen to unemployment over the next twelve months?"2 A higher score means that there will be more unemployment and a lower score means there will be less. For the period from January 1985 to November 2017, the UK series averaged 22 while the Eurozone series averaged 25.

Notably, both series started to rise from the end of 2007, giving an early warning that unemployment was set to rise. The data are timely and are available within a month and don't get revised. The two series have moved closely together until recently. Of note is that the series started to rise in the UK from around the middle of 2015; it has remained elevated since the Leave vote. The fear series has fallen since the middle of 2016 as the Eurozone economy improved.

\section{Measuring Underemployment}

In previous issues of this Review (Bell and Blanchflower, 2011, 2013, 2014 and Blanchflower, 2015), we have argued that measures of labour market slack which focus on the extensive margin of the labour market fail to capture important changes that have taken place on the internal margin. Our measure was discussed recently in ONS (2017). Thus, for example, workers who are constrained from supplying their desired working hours at the going wage rate by the nature of their employment are unlikely to press for higher hourly rates which may reduce their hours further. This differs from the argument that higher unemployment creates greater competition for those in work and therefore weakens their bargaining power. Nevertheless, where employee control over the pattern and length of working time is weak, supply constraints on hours may also be a potent mechanism for weakening wage demands.

\footnotetext{
${ }^{1}$ Source: Table 2.2 Trade Union membership 2016, Statistical Bulletin, Department for Business, Energy \& Industrial Strategy, May 2017.

2 The EU provides a methodological guide explaining how the scores are constructed. https://ec.europa.eu/info/business-economy-euro/indicators-statistics/economic-databases/business-andconsumer-surveys_en
} 
Based on this argument, we developed an underemployment index which takes into account how much workers wish to increase or decrease their current hours of work at the going wage rate. We did this using the micro-data from the UK Labour Force Survey. To maintain compatibility between the unemployment rate and the underemployment rate, our measure of underemployment included not only the expressed wishes of workers to change their working time, but also the implied number of hours that the unemployed would work were they to find a suitable job match. Seasonally adjusted estimates of our underemployment rate from 2002Q1 to 2017Q3 are shown in Figure 3, along with the unemployment rate.

It is clear from Figure 3 that after considerable divergence during, and in the aftermath of, the Great Recession, the underemployment rate implied a considerably greater degree of slack in the UK labour market than did the unemployment rate. However, the two rates have recently converged, such that, in 2017 Q3, the differed by only 0.25 per cent. Their recent convergence is due to expressed wishes for increased hours being almost exactly offset by the desire to decrease hours. When this occurs, our underemployment rate mirrors the unemployment rate.

Figure 4 compares the aggregated desired increase in hours alongside the equivalent decrease in hours as expressed by workers in the Labour Force Survey. The time series for more hours shows a marked change in 2008 , at the start of the recession, with a substantial rise in the number of additional hours being sought. In contrast, while there was some reduction in the aggregate decrease in hours sought by workers, the change in this time series was smaller. Since 2013 the series have converged, such that by 2017 the difference between them was negligible. However, prior to the recession, the "normal" relationship between these aggregates seems to have been that the aggregate desire for fewer hours considerably exceeded that for more hours.

Between 2002 and 2008, the average weekly desired reduction in hours, exceeded the desired increase by around 2.8 million hours per week. If one focuses on the demand for more hours, its average level in 2017 of 37.7 million hours per week substantially exceeded the average in the pre-recession period of 25.6 million hours per week. It appears that this indicator, which focuses only on the difference between the desired hours and actual hours of the employed, has the characteristics of having increased markedly when the recession occurred and still remains substantially above its pre-recession level while the more conventional metrics of labour market slack currently indicate a very tight labour market.

The continued high level of demand for additional hours is consistent with the data on the numbers of workers who wanted a full-time job but accepted a part-time job. This measure only counts those who want more hours and excludes those who want fewer hours. It also does not specify whether they would currently answer this question in the same way. Over the period 2001-2008 their number averaged 604,000. It rose to a peak of 1,462,000 in August-October 2013 , before dropping to 996,000 four years later. Figure 5 shows that, as a percentage of total employment, the numbers who accepted a part-time job when they would have preferred a full-time post is still well above its pre-recession rate.

Another way to conceptualise the data on the difference between actual and desired hours is in relation to quality of job match. Individuals will include satisfaction with working time when assessing the overall quality of a job match. Deviations from desired hours, positive or negative, will have a negative welfare effect. They can choose to quit in response to hours disequilibrium. But if employers are monopsonistic, as described by Manning (2003) for example, willingness to quit will be weakened and employers may opt to vary hours in response 
to demand shocks to maximise short-run profits, particularly if they have not invested heavily in worker-specific human capital.

For low-paid workers that have experienced unemployment, the increased conditionality of the UK benefits regime may reduce the credibility of quit threats. Sanctions with the Jobseekers Allowance benefit peaked at 900,000 during 2013 when total unemployment averaged 2.47 million. Caliendo at al (2013) show that increased benefit duration can lead to better job matches. If the reverse is true and duration conditionality has increasingly applied to the UK benefits system, then large numbers of workers may have made suboptimal job matches, including those which do not match their working time preferences.

Monopsony may also explain why working longer than desired hours is a persistent feature of the UK labour market. Faced with an upward sloping labour supply curve, employers may feel able to increase working time without inducing quits. As we shall see in the next section, the characteristics of those who seek more hours differ substantively from those seeking fewer hours: employers may be able to use knowledge of these differences to their advantage in order to induce workers to adjust their working hours. Before we examine these characteristics, however, note that since the recession there has been a sustained increase in the "disequilibrium" of working time (the aggregate of desired more hours and desired fewer hours), from an average of 57 million per week from 2002 Q1 to 2008 Q1 to 74 million per week between 2014 Q1 and 2017 Q3.

\section{Characteristics of those who want more hours}

In our previous articles, we briefly commented on the characteristics of workers who desire more hours. Thus, for example, we argued that the young are more likely to wish to extend their working week than older workers, who are more likely to wish to reduce their hours. In this contribution, we investigate this issue more comprehensively to understand why there appears to have been an increase in the demand for additional working time. This involves firstly identifying the characteristics of extra-hours workers and secondly the factors which explain how many additional hours they want to work. This involves estimating model with a large number of zeros coupled with non-negative responses. We estimate this using a two-part model (see Duan et al (1984) and Belotti (2015) for a discussion of its properties).

The first part is a probit model that seeks to identify those variables associated with the probability of a worker seeking increased working time. Thus, the dependent variable takes the value 1 if the respondent expresses a wish to work more hours in the relevant quarter and zero otherwise. The second part is a regression model, that identifies characteristics associated with the quantity of additional hours desired, conditional on expressing a wish to extend working time. The dependent variable is thus the number of hours that those expressing a wish to work longer would like to work. Note that in line with Angrist (2001), we do not interpret our results as implying causality. Table 1 reports the results of this two-part model for the pre-recession period, 2002-2007 and the subsequent slow recovery between 2008 and 2017. The right-hand side variables comprise age bands, qualifications, region, length of job tenure, gender, whether born outside the UK, whether married or living together, and if self-employed.

We can also estimate a similar model for those wishing to work fewer hours. For example, we have previously suggested that older workers are more likely to express a preference for fewer hours. Table 1 therefore also includes estimates for two-part models for those wishing to reduce their hours for the periods 2002-2007 and 2008-2017. We use the same right-hand side 
variables to help identify which individual characteristics discriminate between those who wish a longer working week and those who wish a shorter working week.

Note that for each model, the number of observations in the probit model substantially exceeds the number in the regression part, indicating that only a relatively small proportion of the workforce wish to change their hours. For the period 2002-2007, only $10.1 \%$ wish to reduce their hours: this fell to $9.1 \%$ post-recession. Only $7.8 \%$ expressed a wish to increase their hours pre-recession. However, this proportion increased substantially to $11.5 \%$ in the period 2008 2017. These proportions imply firstly that the distribution that we seek to model is dominated by an excess of zeros and secondly that there has been a significant increase in the proportion of workers expressing a wish to work more hours in since 2008. Thus, the increase in the number of workers that wish to work longer must be an important part of the explanation for the aggregate increase in the demand for extra working time. This is captured in the first (probit) part of our model. The second (regression) part identifies whether, conditional on workers wishing to vary their hours, there has been a change in the number of hours that they wish to work more (or less).

For the period 2001-2007, the probit estimates show that workers aged 16 to 49 are significantly more likely to express a wish to increase their hours at their current pay rate than those aged 50+, while the same group is significantly more likely to wish for hours reductions. Similarly, qualifications have a symmetrical effect. The less qualified are more likely to wish to increase their hours, and they are less likely to desire a reduction in their working time.

Similarly, those with shorter tenures are more likely to wish to increase their working time whereas those who have more than 10 years tenure are more likely to seek fewer hours. Longtenure may imply a successful job match which in turn reduces the demand for additional hours. However, this explanation fails to capture why long tenure workers are significantly more likely than those with short tenures to seek fewer hours.

Females are somewhat more likely than males to seek longer working hours, but they are also more likely to seek fewer hours. Being married reduces the probability of seeking more hours and increases the desire for fewer hours. Workers born outside the UK are significantly more likely to seek more hours and significantly less likely to wish to reduce their hours. Finally, the self-employed are more likely to seek increases in their working time and less likely to wish to reduce their hours. Desire to work longer may reflect intrinsic motivation among the selfemployed, but possibly also a lack of demand for the services they provide. Unfortunately, our data do not distinguish whether those who describe themselves as self-employed might more accurately be defined as "dependent contractors", in the terminology of Taylor (2017). His report suggests that this group have particularly weak control over their working conditions, including hours of work.

Comparing coefficients from the probit models for the pre-recession and post-recession periods, suggest that the determinants of whether workers seek to vary their hours have remained broadly stable. Tenure and age effects have declined slightly for those seeking more hours: how long someone has been in a job, or how old she is, has become a less important determinant of whether they wish to extend their hours. There is been virtually no change in the characteristics of those seeking fewer hours with the exception that the self-employed and those born outside the UK have become even less likely to seek a reduction in hours. The largest difference between the pre-recession and post-recession estimates are the changes in the constant term in the "more hours" equations. These cannot be ascribed to variables included 
in the estimated models may, for example, reflect the effects of fear of unemployment which might cause workers to express a wish to be available for additional duties.

The second influence on aggregate desired hours is the number of additional, or fewer, hours that those seeking extra hours wish to work. The quarterly average of these is shown in Figure 6 for the period 2002-2017. For those seeking more hours, it increased prior to the recession, peaked at the beginning of 2014, and subsequently plateaued at around 11.7 hours per week. Perhaps surprisingly, the average desired reduction in working hours also increased around the recession, albeit to a much smaller extent than the mean desired increase in working time. These effects are picked up in the second (regression) part of our model shown in the lower part of Table 1, whose coefficients estimate for the change in desired hours associated with the various individual characteristics. Thus, the coefficients in this part of Table 1 can be interpreted as the number of hours (more or less) associated with the relevant characteristic.

Thus, conditional on wishing to extend working time, the young (those aged 16-24) are willing to work almost an hour longer than their older counterparts. Conditional on a desire for reduced hours, they also seek a smaller reduction in their working time than older workers. Those with no qualifications or "other" qualifications wish to work significantly more hours than those with degrees. However, for those seeking fewer hours, the relationship to qualifications is less clear. Those with tenure of five years or more, even if they wish to work longer, seek significantly fewer additional hours than their shorter-tenure counterparts, again perhaps indicating a better match for their working time preferences. Although women are more likely to seek more hours than men, their preference is for fewer additional hours than men. Similarly, those who are married wish for a smaller increase in their hours conditional on an increase in their hours and a larger decrease conditional on a reduction in their hours.

Those born outside the UK seek both a greater increase in their hours when seeking increased hours and a greater reduction when seeking fewer hours. The self-employed wish to work around two hours more hours than employees. But, conditional on a desired reduction in hours, they also seek a significantly greater reduction in their working time. While these results wishing both a greater increase and a greater decrease - may seem paradoxical, they are consistent with these groups experiencing greater variation in both their working time and their incomes than other workers. Those who are demand constrained will seek more hours to boost their incomes, whereas those who work much longer hours than typical employees may seek a larger reduction in their working time even at the cost of lower gross income.

\section{Conclusion}

Part of the puzzle for weak wage growth in the UK and elsewhere continues to be high levels of underemployment. The numbers who report they are part-time and want full-time are well above pre-recession levels. The gap between our measures of the number of additional hours required by those who want more hours and the number who want less has narrowed recently. Neither of these measures have returned to their pre-recession levels. In our view, underemployment remains an important, but not the sole, factor in explaining the $2 \%$ wage norm that continues to exist in the UK. However, it is not sufficient to explain the current inertia in wage settlements which must also reflect a degree of anchoring around this wage norm, irrespective of labour market conditions. Change from the current wage norm may require a more dramatic change in the economic outlook than the UK is currently experiencing. 
Table 1: Characteristics of Those Wishing to Work More Hours or Fewer Hours, 2002-2007 and 2008-2017

\begin{tabular}{|c|c|c|c|c|}
\hline Variable & $\begin{array}{c}\text { Fewer Hours } \\
2002-2007\end{array}$ & $\begin{array}{l}\text { Fewer hours } \\
2008-2017\end{array}$ & $\begin{array}{l}\text { More hours } \\
2002-2008\end{array}$ & $\begin{array}{l}\text { More hours } \\
2008-2017\end{array}$ \\
\hline \multicolumn{5}{|l|}{ probit } \\
\hline Ages 16-24 & $-0.579 * * *$ & $-0.670 * * *$ & $0.330 * * *$ & $0.298 * * *$ \\
\hline Ages $26-49$ & $-0.189 * * *$ & $-0.287 * * *$ & $0.111 * * *$ & $0.081 * * *$ \\
\hline NVQ level IV & $-0.099 * * *$ & $-0.054 * * *$ & $0.119 * * *$ & $0.144 * * *$ \\
\hline NVQ level III & $-0.115^{* * *}$ & $-0.109 * * *$ & $0.118 * * *$ & $0.163 * * *$ \\
\hline Trade apprentice & $-0.193 * * *$ & $-0.131 * * *$ & $0.087 * * *$ & $0.124 * * *$ \\
\hline NVQ level II & $-0.206^{* * *}$ & $-0.206^{* * *}$ & $0.197 * * *$ & $0.249 * * *$ \\
\hline Other qualification & $-0.257 * * *$ & $-0.226 * * *$ & $0.247 * * *$ & $0.235^{* * *}$ \\
\hline No qualification & $-0.375 * * *$ & $-0.389 * * *$ & $0.229 * * *$ & $0.249 * * *$ \\
\hline 3 to 6 months & $0.061 * * *$ & $0.067 * * *$ & $-0.057 * * *$ & $-0.050 * * *$ \\
\hline 6 months to 1 year & $0.089 * * *$ & $0.096 * * *$ & $-0.121 * * *$ & $-0.098 * * *$ \\
\hline One year to 2 years & $0.148 * * *$ & $0.154 * * *$ & $-0.208 * * *$ & $-0.172 * * *$ \\
\hline Two years to 5 years & $0.192 * * *$ & $0.193 * * *$ & $-0.307 * * *$ & $-0.280 * * *$ \\
\hline Five years to 10 years & $0.254 * * *$ & $0.258 * * *$ & $-0.434 * * *$ & $-0.395 * * *$ \\
\hline 10 years to 20 years & $0.321 * * *$ & $0.324 * * *$ & $-0.561 * * *$ & $-0.510 * * *$ \\
\hline More than 20 years & $0.372 * * *$ & $0.393 * * *$ & $-0.717 * * *$ & $-0.699 * * *$ \\
\hline Female & $0.115 * * *$ & $0.102 * * *$ & $0.133 * * *$ & $0.118 * * *$ \\
\hline Born outside the UK & $-0.124 * * *$ & $-0.212 * * *$ & $0.243 * * *$ & $0.254 * * *$ \\
\hline Married & $0.127 * * *$ & $0.148 * * *$ & $-0.158 * * *$ & $-0.180 * * *$ \\
\hline Self-employed & $-0.100 * * *$ & $-0.153 * * *$ & $0.177 * * *$ & $0.214 * * *$ \\
\hline Constant & $-1.452 * * *$ & $-1.542 * * *$ & $-1.315^{* * *}$ & $-1.093^{* * *}$ \\
\hline $\mathrm{N}=$ & 914,514 & 121,8007 & 90,509 & $1,209,480$ \\
\hline Pseudo $\mathrm{R}^{2}$ & 0.0367 & 0.0468 & 0.0585 & 0.0531 \\
\hline
\end{tabular}

regression

Ages 16-24

$\begin{array}{ll}-1.370 * * * & -1.134 * * * \\ -0.508^{* * *} & -0.687 * * * \\ -0.199 * & 0.092 \\ -0.324 * * * & -0.176^{* *} \\ -0.273^{* *} & -0.248^{*} \\ -0.361 * * * & -0.247 * * * \\ 0.040 & -0.150^{*} \\ -0.016 & 0.374 * * * \\ -0.109 & -0.070 \\ -0.156 & 0.060 \\ 0.190 & 0.235 \\ 0.095 & 0.247 \\ 0.294 & 0.105 \\ 0.162 & 0.149 \\ 0.485 * * & 0.261 \\ -0.279 * * * & -0.387 * * * \\ 0.619 * * * & 0.225 * * \\ 0.410 * * * & 0.263 * * *\end{array}$

$0.705^{* * * *}$

$0.890^{* * *}$

Ages 26-49

NVQ level IV

NVQ level III

Trade apprentice

NVQ level II

Other qualification

No qualification

3 to 6 months

6 months to 1 year

One year to 2 years

Two years to 5 years

Five years to 10 years

10 years to 20 years

More than 20 years

Female

Born outside the UK

Married

$0.410 * * *$

$0.215^{*}$

0.017

$0.308^{*}$

$0.198^{*}$

$0.292 * *$

0.062

0.184

$0.331 * *$

$0.434 * * *$

$0.483 * * *$

$0.946 * * *$

$0.788 * * *$

$1.321 * * *$

$1.687 * * *$

$-0.711 * * *$

$-0.363 * * *$

$-0.979 * * *$

$-0.796 * * *$

$-1.185^{* * *}$

$-1.290 * * *$

$-1.716^{* * *}$

$-1.782 * * *$

$-2.341 * * *$

$-2.461 * * *$

$-2.845 * * *$

$-2.962 * * *$

$-3.038 * * *$

$-3.285^{* * *}$

$-0.441 * * *$

$-0.681 * * *$

$1.342 * * *$

$1.204 * * *$

$-0.644 * * *$

$-0.751 * * *$ 


\begin{tabular}{rcccc} 
Self-employed & $4.208 * * *$ & $3.439 * * *$ & $2.016 * * *$ & $1.912 * * *$ \\
Constant & $10.329 * * *$ & $11.011 * * *$ & $13.860 * * *$ & $15.209 * * *$ \\
\cline { 2 - 5 } Statistics & & & & \\
$\mathrm{N}$ & 92,555 & 110,479 & 71,111 & 138,777 \\
Adjusted $\mathrm{R}^{2}$ & 0.0581 & 0.0406 & 0.0329 & 0.0385
\end{tabular}

Legend: * $\mathrm{p}<0.05 ; * * \mathrm{p}<0.01 ; * * * \mathrm{p}<0.001$.

Source: Labour Force Survey microdata.

Excluded categories: Ages 50-64, Degree, 0-3 months job tenure. Right-hand side variables included regional dummies which are not reported here, but had little impact. 
Figure 1. UK AWE annual wage growth, nominal and real

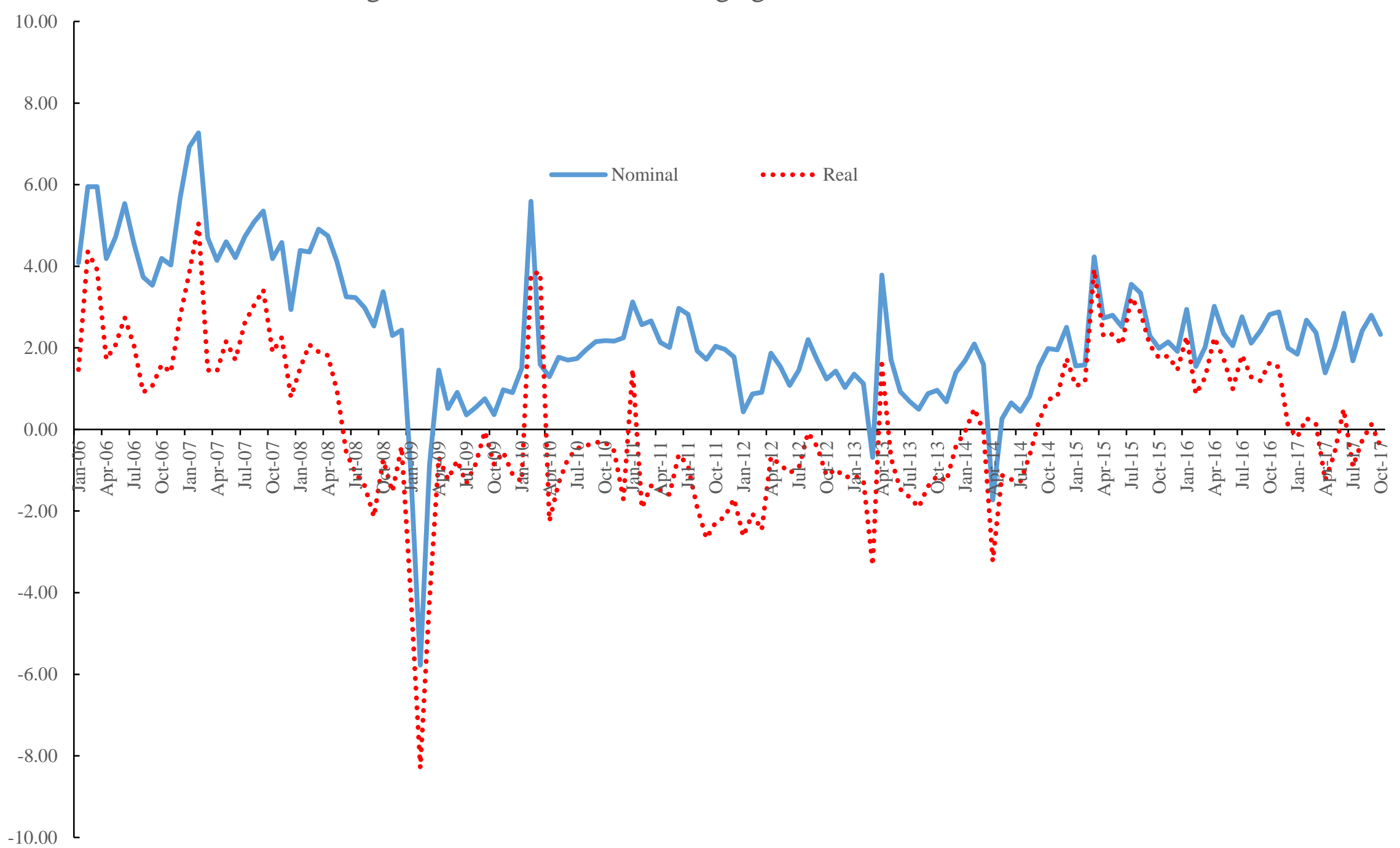


Figure 2. Fear of unemployment - UK and Euro Area

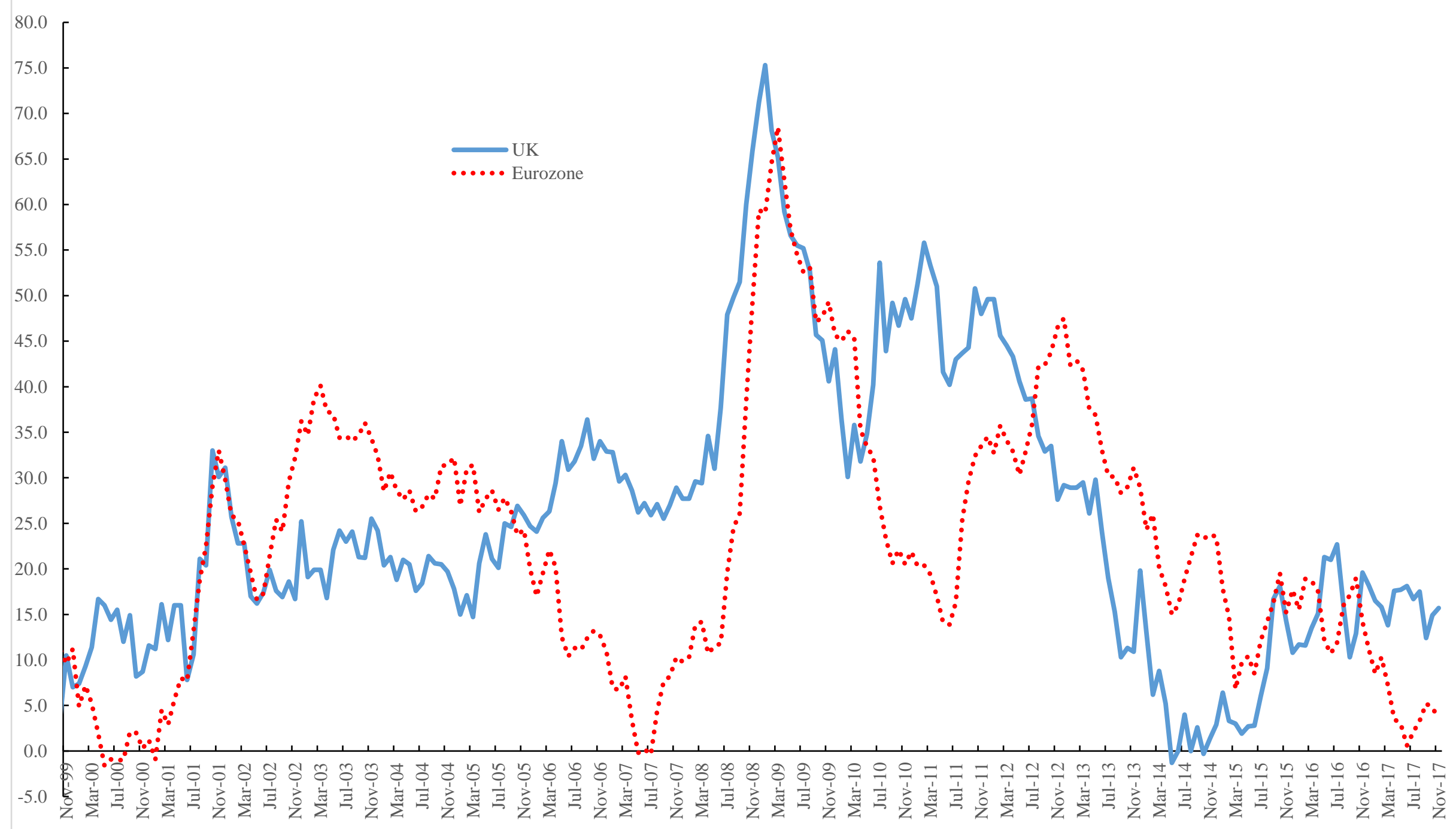


Figure 3. Unemployment and Underemployment Rates 2002-20217

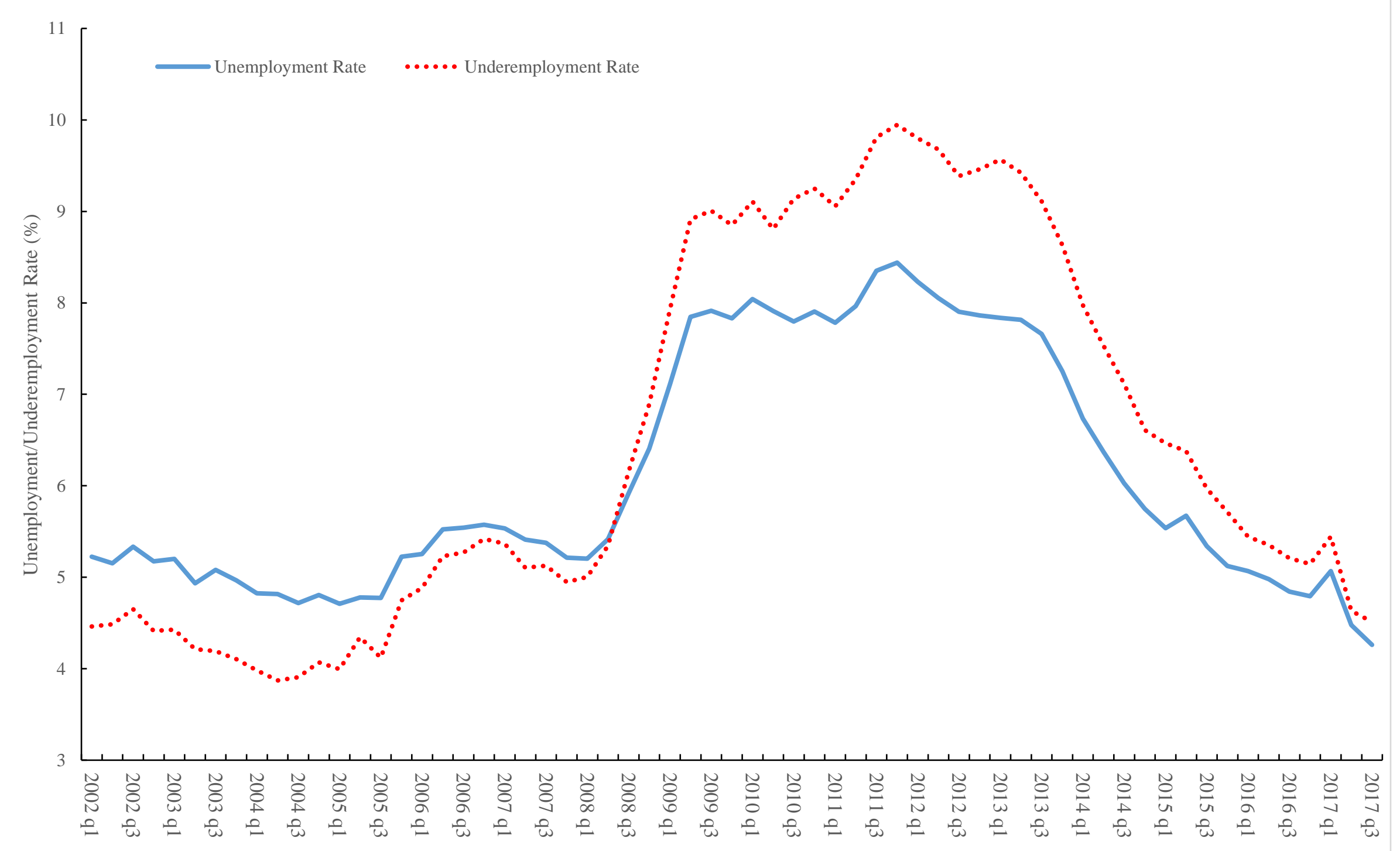


Figure 4: Aggregate desired changes in weekly hours of those who want more and those who want less, 2002-2017

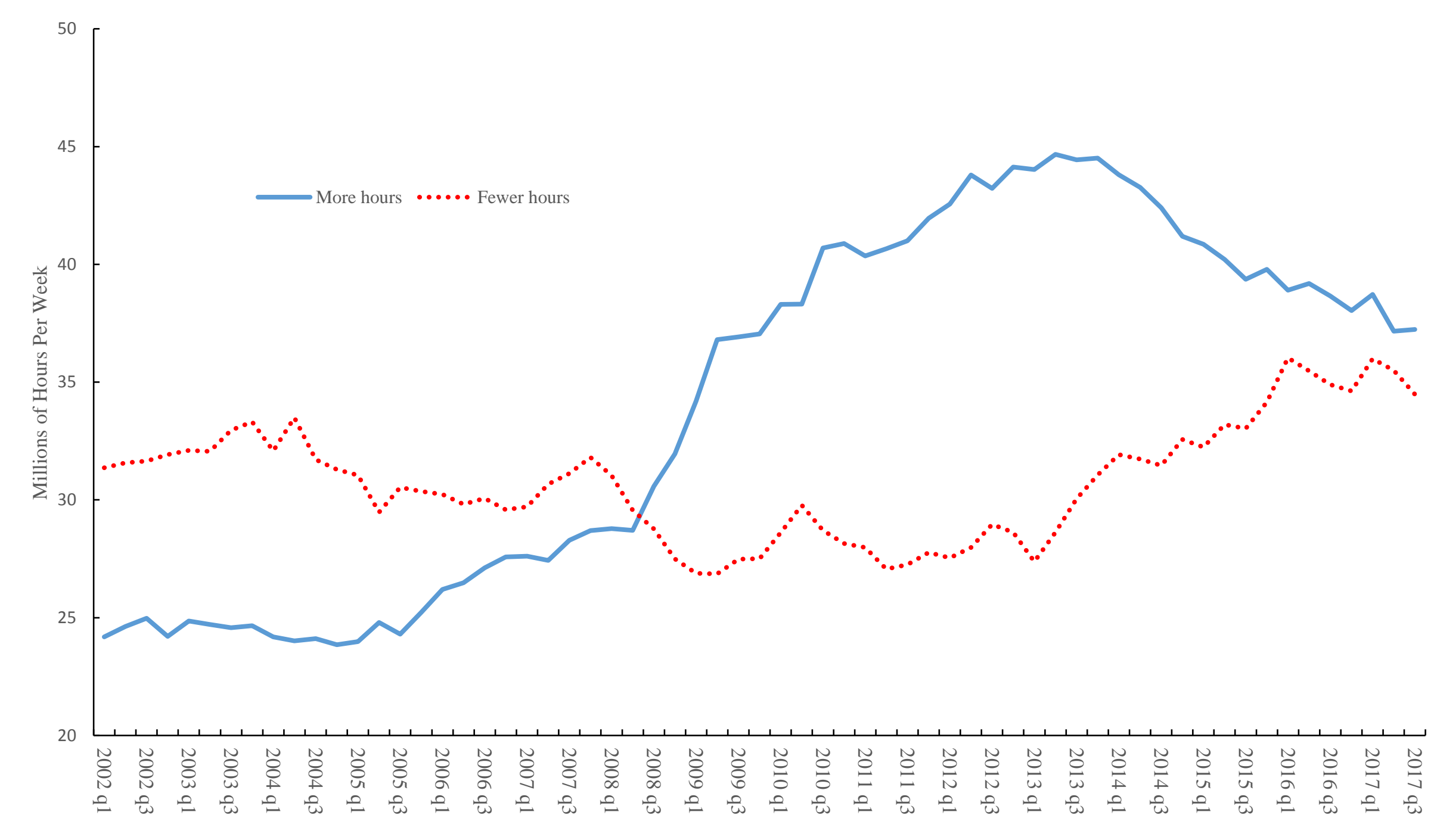


Figure 5. Part-time wanting full-time as percent of total employment

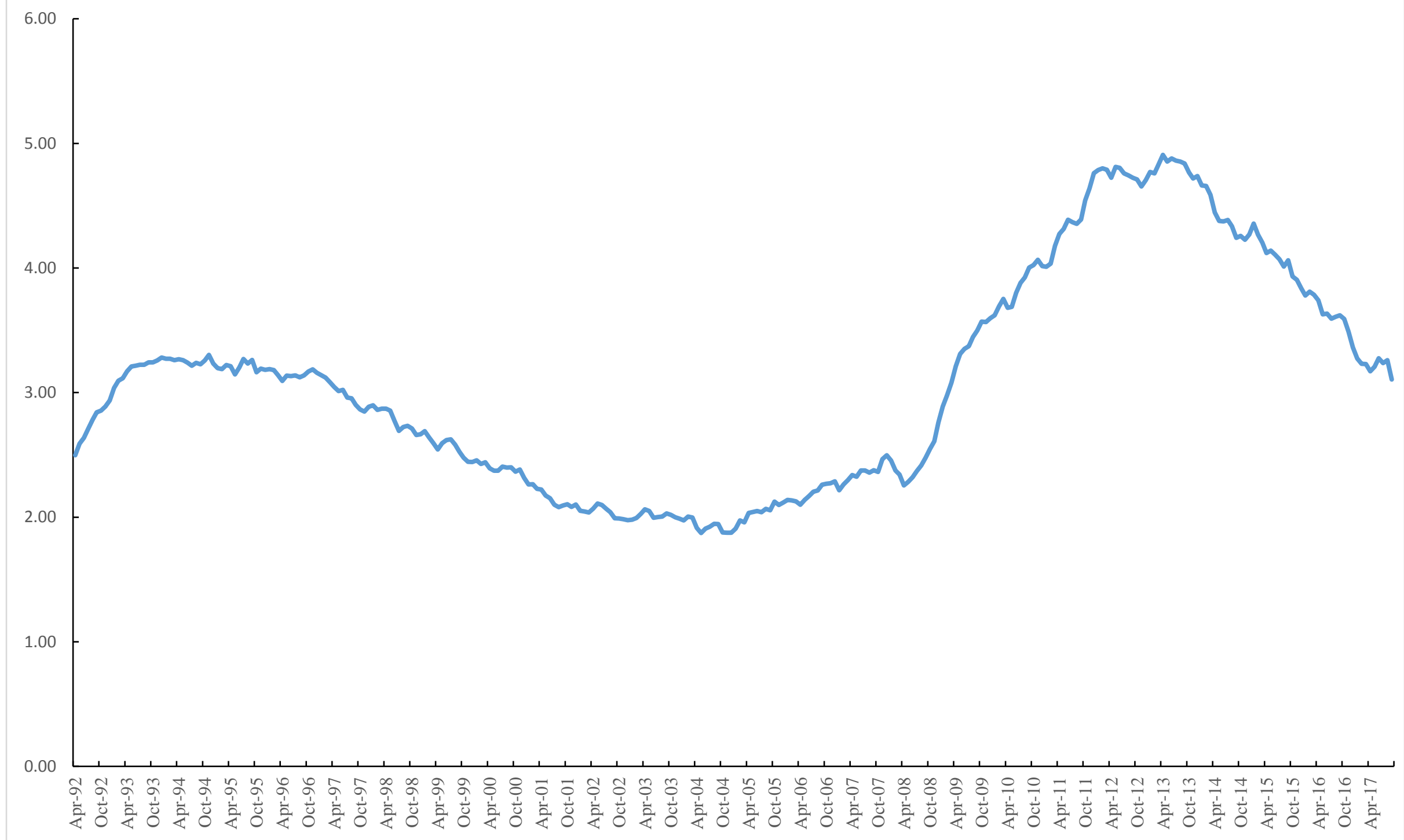


Figure 6: Mean change in desired extra weekly hours 2002-2017

12.5

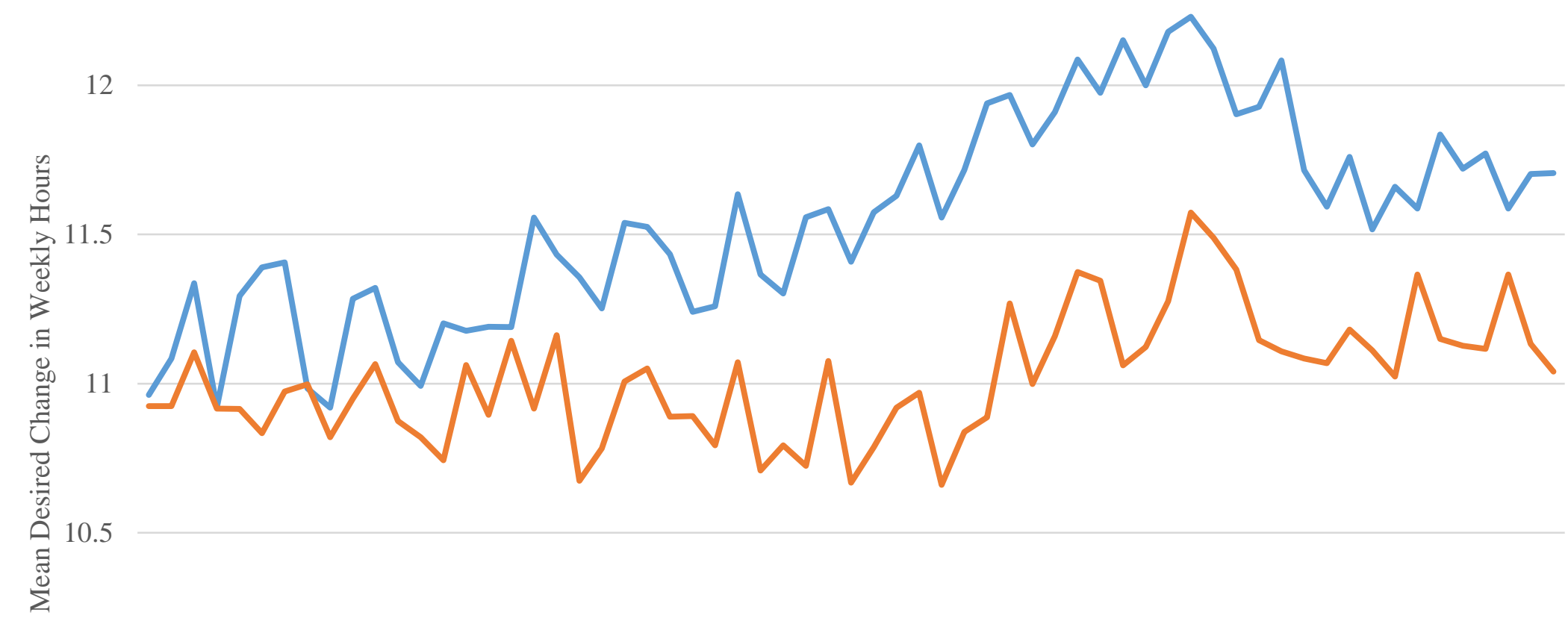

10

9.5

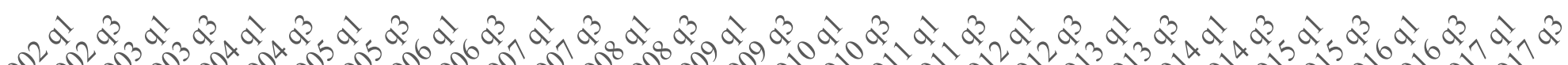

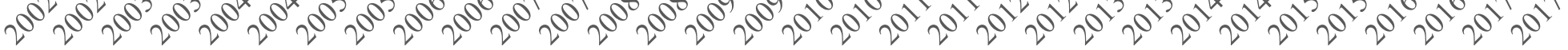

-More Hours — Fewer Hours 


\section{References}

Angrist, J. D. (2001). 'Estimation of limited dependent variable models with dummy endogenous regressors: simple strategies for empirical practice', Journal of Business and Economic Statistics, 19.1, 2-28.

Belfield, C., R. Blundell, J. Cribb, A. Hood, R. Joyce and A.N. Keiller (2017), 'Two decades of income inequality in Britain: the role of wages, household earnings and redistribution', Economica, Volume 84, Issue 334, 157-179, April.

Bell, D.N.F., and D.G. Blanchflower (2014), 'Labour market slack in the UK,' National Institute Economic Review, 229, F4-F11

Bell, D.N.F and D.G. Blanchflower (2013), 'Underemployment in the UK revisited,' National Institute Economic Review, 224, F8-F22.

Bell, D.N.F and D.G. Blanchflower (2011), 'Underemployment in the UK in the Great Recession,' National Institute Economic Review, 215, R23-R33.

Belotti, F., P. Deb, W.G. Manning and E.C. Norton (2015), 'Two-part models', Stata Journal, 15,1, 3-20.

Blanchflower, D.G. (2015), 'As good as it gets? The UK labour market in recession and recovery,' National Institute Economic Review, 231, February, F76-F80.

Blanchflower, D.G. and C. Shadforth (2009), 'Fear, unemployment and migration', The Economic Journal, 119 (535), February, F136-F182.

Caliendo, M., Tatsiramos, K., and Uhlendorff, A. (2013), 'Benefit duration, unemployment duration and job match quality: a regression discontinuity approach', Journal of Applied Econometrics, 28(4), 604-627.

Dolton, P., Hantzche, A. and A. Kara "Follow the Leader? The Interaction between Public and Private Sector Wage Growth in the UK"

Duan, N., W.G. Manning Jr., C.N. Morris and J.P. Newhouse (1984), 'Choosing between the sample-selection model and the multi-part model', Journal of Business and Economic Statistics, 2, pp. 283-289

Manning, A. (2003). 'Monopsony in motion: Imperfect competition in labor markets'. Princeton University Press.

Office of National Statistics (2017), 'Measuring labour market underutilisation,' Economic Review, October.

Roos, M. W., and Luhan, W. J. (2008), 'Are expectations formed by the anchoring-andadjustment heuristic? An experimental investigation', Ruhr Economic Paper No. 54.

Saunders, M. (2017), 'The labour market', Speech given at the Resolution Foundation, Bank of England, $13^{\text {th }}$ January. 
Taylor, N. (2017). "Good work: the Taylor review of modern working practices", Accessed at: http://bit.ly/2sROQk8 Accessed on January 8, 2018. 